\title{
¿Leer para qué? Hacia una política de la lectura
}

\author{
Sarah Corona Berkin* \\ saco100@terra.com.mx
}

Este artículo propone rescatar la dimensión política del lenguaje escrito en la enseñanza de la lectoescritura. A partir de la revisión de distintos abordajes teóricos en torno a la escritura, la autora reflexiona sobre su uso en el espacio público. A manera de ejemplo, se ofrecen algunos resultados de su investigación con jóvenes de distintos grupos sociales sobre sus competencias lectoescritoras. Se muestra el impacto de la valoración de dicha forma comunicativa en la participación de los jóvenes en el espacio público.
This article wishes to restore the political dimension in teaching written language. The author offers different theoretical perspectives on writing and underlines it's use in the public arena. Some examples of written language done by dissimilar social groups of young people show the impact that political use has in writing and participating in public space.

¿Leer para qué? Muchas veces nos topamos con respuestas tautológicas que proveen de pocas claves para orientar nuestra práctica educativa: saber leer para leer. Aprender a leer para saber leer. Fomentar la lectura para practicarla. Mi propósito es compartir algunas hipótesis en torno al aprendizaje de la lectoescritura ${ }^{1}$

*Universidad de Guadalajara.

${ }^{1}$ Me refiero a la lectura y a la escritura, como partes de un proceso paralelo y constitutivo de la alfabetización. En el futuro me referiré a la lectoescritura como una competencia integrada ya que se busca que se conozcan, de forma activa, ambos saberes. 
a partir de la relevancia político-comunicativa del lenguaje escrito. Por relevancia político-comunicativa entiendo la pertinencia de la lectoescritura que encuentra su auténtica expresión en el espacio público, donde los muchos distintos que somos expresamos nuestras diversas necesidades, deseos y miradas y nos ponemos de acuerdo para vivir en conjunto.

Mi propuesta tiene que ver con la recreación del espacio público de la lectoescritura, así como de la enseñanza de la misma. Con Jesús Martín Barbero veo la necesidad urgente de considerar la comunicación a partir de "la reconstrucción de lo público, la constitución de los medios y las imágenes en espacio de reconocimiento social, y las nuevas formas de existencia y ejercicio de la ciudadanía” (Martín Barbero 2001: 7).

Las cifras que se manejan en torno a la lectura en México son dudosas. Poco se invierte en ese tipo de información "en un país donde las estadísticas de lectura están pendientes" (Salazar 2003: 39). Sin embargo sabemos que poco o nada se lee cotidianamente, y menos aún se escribe. De acuerdo con cifras de la UNESCO, "en México se leen en promedio 2.8 libros per capita" (idem). Los esfuerzos individuales e institucionales son enormes, se publican millones de libros por año (121 millones 100 mil libros de texto gratuitos y materiales educativos para preescolar y primaria sólo para el ciclo escolar 2002-2003 (conaliteg.gob.mx). Se invierte en técnicas pedagógicas, se dedica tiempo e imaginación a la enseñanza, pero los resultados son limitados. En 2003, México “quedó en el lugar 34 entre los 41 países que participaron en el estudio de conocimientos escolares de la Organización para la Cooperación y el Desarrollo Económicos" (Herrera 2003: 46).

La respuesta de una niña de tercer año de primaria a la pregunta “¿Cuáles son los libros para niños y cuáles son para adultos", sintetiza el objetivo de la lectura para muchos: "Los libros son sólo para niños porque sólo ellos necesitan aprender a leer y escribir, los adultos ya saben", no necesitan libros (Corona y DiezMartinez 1993: 63). De esta manera podemos inferir que leer y escribir, en su calidad de descifrado, son útiles para objetivos tan concretos como "saber a qué camión subirse" (idem). 
Por otro lado, también reconocemos un debilitamiento del espacio público de la lectoescritura. Los best-sellers definen lo "leíble" y lo "escribible", los periódicos controlan lo decible, la política actualmente se construye entre los vendedores de imagen y las contiendas mediáticas. La reflexión escrita, el debate de ideas, la controversia seria, tienen pocos espacios de expresión. Por ello nuestra propuesta tiene dos bordes: la enseñanza de la lectoescritura en su dimensión política y la recreación de un espacio público propio para el lenguaje escrito.

Primero, a partir de Hanna Arendt (1993, 1996, 1997, 2001) dirijo mi atención al espacio público, luego esbozaré mi propuesta y, en un tercer momento, expondré ejemplos para ilustrar distintas apropiaciones del lenguaje escrito por distintos grupos sociales.

\section{¿CuÁl es la importanCia del ESPACIO PÚbliCo?}

Por democracia, actualmente se entiende la voz ciudadana de las mayorías. Sin embargo, en una situación donde la clase política asume los poderes públicos y mantiene dependiente de ella a una sociedad civil sin posibilidades de debatir ni participar en los acuerdos nacionales, se imposibilita la existencia de una esfera independiente dedicada al ejercicio de la democracia por los ciudadanos.

La forma de interpretar la democracia por parte del poder se apoya en la construcción de una "opinión pública" y en la eliminación de la opinión que no es mayoritaria. La construcción de la llamada "opinión pública" es responsabilidad de las corporaciones comunicativas, cuyos valores son más mercantiles que democráticos. Así, las encuestas de opinión han llegado a ser la expresión "democrática" de los medios masivos de comunicación.

Desde el campo de la comunicación política, Wolton considera que "la democracia de masas" que vivimos hoy, es históricamente natural y que son sólo tres los actores que tienen legitimidad para expresarse públicamente sobre lo político, es decir "los políticos, los periodistas y la opinión pública a través de los sondeos" (Wolton 1998: 110). Quedan, para el autor, excluidos los movimientos sociales, agrupaciones, etcétera, que son "opinio- 
nes minoritarias" y, con este criterio, no merecedoras de una opinión pública.

En una posición opuesta, Alain Touraine observa que "mientras la filosofía de la historia nos mostraba la imagen de una humanidad cada vez más homogénea, gobernada por la razón, por el interés o por la paz y ya no por las creencias o por tradiciones culturales comunitarias" y distintas unas de otras, en la actualidad "la modernización política (se representa) como el deterioro veloz de las normas, de los valores y de las formas de organización social consideradas racionales, y por lo tanto (se define) como la gestión de la diversidad" (Touraine 1999: 45-46).

En este sentido, en el momento actual cuando múltiples identidades buscan su reconocimiento y participación sociales, cabe agregar que muchas veces los sondeos de opinión, como mecanismos para dar visibilidad a las necesidades ciudadanas, son una simulación, como el mismo uso del número como prueba de la retórica científico-ideológica, donde no se cuestionan ni los métodos ni el origen de las opiniones que desean ser conocidas. Para Bourdieu (1990: 239-250) "no existe la opinión pública" por lo menos debido a tres supuestos erróneos en el concepto de los sondeos de opinión: 1) se considera en dichos sondeos que cualquiera puede tener una opinión sobre cualquier asunto y se excluyen las "no respondió", como si todo mundo tuviera exclusivamente una opinión favorable o desfavorable; 2) todas las opiniones tienen el mismo valor y da lo mismo a todas las personas opinar sobre un partido de futbol o uno político, o bien se suman personas que miden en kilómetros y otras en centímetros, y 3) se considera que hay consenso entre los entrevistados acerca de los problemas que se eligen para el sondeo, cuando la problemática dominante de los sondeos es la que interesa al poder y no es del mismo interés para los diversos grupos sociales.

Esta definición de la opinión pública está muy alejada de lo que consideramos participación política con la diversidad en el espacio público. Porque el auténtico espacio público es el lugar que garantiza por lo menos dos derechos: la aparición y reconocimiento de las diferencias y un espacio común a todos. De esta 
manera, con la pérdida del espacio público en las sociedades modernas se debilita la participación, ya que no hay espacio de reconocimiento de las diferencias ni lugar para entablar el diálogo.

El ser humano tiene necesidad del "otro" para recrear su identidad. Pero vemos que los medios masivos de comunicación eligen a quiénes tienen visibilidad y a quiénes tienen la disposición para existir.

En el ámbito de la cultura, como en el de las subjetividades, la mirada exterior es el mecanismo más poderoso de la comprensión. Una persona y una cultura se descubren plena y profundamente sólo a los ojos de otra. Entre las distintas miradas se establece el diálogo: "Planteamos preguntas nuevas a una cultura ajena, que ella misma no se había planteado, buscando en ella respuestas a nuestras preguntas, y la cultura ajena nos responde descubriendo ante nosotros sus nuevos aspectos, las nuevas profundidades del sentido" (Bajtín 2000: 159).

Como espacio común, el espacio público, a diferencia de la "opinión pública", proporciona el contexto imprescindible para que pueda surgir la acción política. La creación de numerosos espacios donde todos puedan exponerse permite adoptar la acción y el discurso como forma de estar juntos. Localizar estos espacios, conocerlos, proporcionar diferentes formas comunicativas, entre ellas la lectoescritura de carácter imprescindible, es tarea nuestra.

En el espacio público, como nosotros lo imaginamos, más allá de la contemplación de las diferencias y de la búsqueda de valores universales compartidos por todos, se exploran los puntos de intersección, los valores comunes y las resonancias entre una cultura y otra y, mediante la deliberación colectiva, se resuelven los asuntos de interés común. Los medios de comunicación, en su afán por fundir todas las culturas en una que responda a sus intereses de mercado, empobrecen los acontecimientos, rechazan la visibilidad a la diversidad y niegan formas políticas de solución.

Por lo tanto, la construcción del espacio público tiene una finalidad: la comunicación. Comunicación donde la contraposición de los sujetos sea el pilar de la construcción de las formas 
creativas de vivir juntos. En el verdadero encuentro en el espacio público, las identidades no se funden ni se mezclan; cada una conserva su unicidad, pero todas, en el diálogo y en el conflicto, se enriquecen mutuamente. En este escenario, leer y escribir son herramientas fundamentales. El carácter político de la convivencia en el espacio público sólo es posible mediante el lenguaje y es gracias a la palabra que el mundo se revela como un espacio habitable por muchos distintos. De esta manera, el "para qué" leer y escribir encuentra una respuesta y la enseñanza de la lengua escrita adquiere sentido si es para forjar una nueva convivencia en el espacio público.

\section{LA LECTOESCRITURA EN EL ESPACIO PÚBLICO}

Encontramos distintos abordajes educativos que consideran el proceso de lectoescritura como vía de acceso a la cultura. El aprendizaje del descifrado y sus estrategias para desarrollar una escritura eficiente; los planteamientos gramaticales o literarios para incitar la lectura y escritura; la promoción de la lectura y de las técnicas de composición (Krashen 1984; Fijalkow 1986), son discusiones en torno a competencias de la lectoescritura que, si bien se preocupan por el correcto leer y escribir, descuidan el entorno particular del joven y la valoración que hace su cultura del medio escrito. Estas posturas apuestan al aprendizaje de habilidades pero las descontextualizan de su relevancia comunicativa.

La disponibilidad de materiales impresos y la escuela ofrecen oportunidades para acceder a las prácticas lectoescritoras; sin embargo, no son suficientes para distribuir la cultura escrita. Ésta depende, argumentaremos, de los factores comunicativos y políticos implícitos en la lectoescritura.

Lectoescritura y poder. La aproximación a la lectoescritura como forma de poder nos arroja otra luz sobre su uso y aprendizaje. En una posición claramente política, Giroux amplía su posición frente a la alfabetización, donde considera que aprender a leer y escribir no es sólo conocer el descifrado; alfabetizar es apren- 
der herramientas que faciliten el pensamiento y acción críticos. Su propuesta, como la de Paulo Freire, implica asimilar la lectura y la escritura a partir de la propia historia, las propias necesidades y su lugar social (Giroux 1998).

Por otro lado, Claude Levi-Strauss describe la función de la escritura como potenciadora del poder. Para el autor, la escritura no se reduce a una técnica informativa y menos a una herramienta para el desarrollo de la humanidad. Rastreando los grandes saltos cualitativos en la existencia humana, considera que éstos se deben a la observación, experimentación y transmisión de los hallazgos y no a la naturaleza intelectual de la escritura. Si bien acepta que la escritura "multiplica prodigiosamente la aptitud de los hombres para preservar los conocimientos" (Levi-Strauss 1992: 323), esta memoria artificial no amplifica la conciencia del pasado, ni la capacidad para organizar el presente y el futuro. Pone en duda la relación escritura-ciencia al advertir que los cinco mil años que separan el invento de la escritura de la ciencia moderna son testimonio de los tumbos entre el conocimiento y la ignorancia y que de ningún modo la aparición de la escritura afirmó un camino constante y ascendente para el pensamiento científico de las muchas veces empantanadas civilizaciones occidentales.

Para el autor, lo que sí acompaña a la escritura es la urbanización y con ella, la división clara entre los que saben leer y escribir y los que no saben. De esta forma, desmitificamos que el aprendizaje y el uso de la lectura y la escritura sean únicamente con fines desinteresados y dirigidos hacia metas de satisfacción intelectual. Sin embargo, estas perspectivas muestran el poder que conlleva la escritura en la configuración de las sociedades, pero no en la apropiación de ese poder por grupos sociales determinados. Mi punto de partida es que, si bien la lectoescritura es cimiento de estructuras sociales, también es herramienta de comunicación entre los múltiples y diversos sujetos que habitamos el espacio público.

Lectoescritura como tecnología. Una vertiente importante para el conocimiento del impacto de la escritura en la cultura la constituyen los estudios sobre la escritura como tecnología 
comunicativa (Havelock, Ong, McLuhan). El conocido proverbio de McLuhan, "el medio es el mensaje", registra la importancia que el autor le otorga al paso del mundo oral al de la escritura, al impreso y al electrónico. De esta forma, para McLuhan son las formas de comunicación, y no los contenidos, los que transforman la sociedad.

Para el autor, el hombre tribal tiene sus sentidos equilibrados: "antes del invento del alfabeto fonético, el hombre vivía en un mundo donde todos sus sentidos eran balanceados y simultáneos, un mundo cerrado de profundidad y resonancia tribal" (McLuhan 1969: 56). Aparece el alfabeto y se cambia el equilibrio del oído por la prominencia del ojo, es decir, se cambia la oralidad por la escritura.

Es necesario señalar ciertos límites al tecnologismo extremo de McLuhan. El autor no considera las condiciones políticas y económicas que han consentido el nacimiento de las tecnologías y, por lo tanto, escapan de su análisis los objetivos militares, mercantiles y de control que motivaron la aparición de determinadas tecnologías en ciertos momentos históricos. En segundo lugar, no considera las condiciones de apropiación de los usuarios y las múltiples puestas en acción de una misma tecnología de acuerdo con los contextos culturales. Finalmente, en su interés por el aspecto tecnológico de los medios, descuida el análisis de los contenidos que marcan también la mirada, el habla y la escritura de los sujetos.

Sin embargo, coincidimos en que las características de la escritura primero, y de la imprenta después, marcan la configuración de una sociedad letrada, agrupada por lenguas nacionales, exigencias de correcta sintaxis y ortografía, separación entre el habla educada y el habla popular, formas nacionalistas de gobierno, industrialización, empleos uniformes, mecanización de los oficios y políticas de educación masiva.

Lectoescritura y contextos comunicativos. El aprendizaje del descifrado de la lectoescritura, el impacto cultural de la escritura como tecnología y la escritura como herramienta de poder y do- 
minación, no agotan su ejecución. ¿Qué escriben y cómo lo hacen distintos grupos sociales? La respuesta tiene que ver con las condiciones materiales de las producciones escritas, en especial del entorno comunicativo que rodea a los distintos grupos. La posición tecnológico-determinista anterior no considera las múltiples aplicaciones de la escritura en diferentes grupos sociales y momentos históricos. Trabajos como los de Ong (1985), McLuhan (1964), Goody (1996) y Havelock (1963), muestran una separación demasiado tajante entre la tecnología de la oralidad y la escritura y sus consecuencias cognitivas en el desarrollo humano y social. Considero que la oralidad y la escritura, más que como modos diferentes de comunicación, deben ser estudiados en sus distintos usos en distintas culturas y momentos históricos.

Para Ruth Finnegan (1988), el impacto de la oralidad y la escritura en el desarrollo de la democracia, de la burocracia y del pensamiento abstracto, tiene que ver con las maneras en que estas formas comunicativas son controladas y utilizadas. Su aporte va en el sentido de confiar menos en el impacto unidireccional de la oralidad y la escritura y tomar en cuenta los usos específicos de cada cultura:

El medio por sí mismo no puede originar las consecuencias sociales, debe ser usado por la gente y desarrollado desde instituciones sociales. La tecnología de la escritura no puede causar cambios sociales. Lo que cuenta es su uso, quién la usa, quién la controla, para qué es usada, cuál es su lugar en la estructura de poder, cuál es su distribución. Son estos factores sociales y políticos los que dan forma a las consecuencias (Finnegan 1988: 41-42).

Al apartarse del determinismo tecnológico, la autora observa con mayor detenimiento los efectos de la tecnología desde los múltiples contextos de la práctica lectoescritora. Sin embargo, creemos que son dos los límites de la propuesta de Finnegan. Por un lado, al separarse del interés por estudiar la especificidad de las tecnologías comunicativas, pareciera que éstas son neutras, vacías, en espera de los usos de control o democráticos, según sea 
el caso cultural e histórico. Creemos que no se puede olvidar que las tecnologías comunicativas no son neutras. Los "inventos" tecnológicos emergen como efecto de condiciones histórico-políticas determinadas, es decir, aparecen revestidas de ciertos intereses que les dan vida y permiten existir. Su surgimiento cumple con necesidades de dominar los espacios, modificar los plazos de transmisión de información, descomponer el tiempo tradicional en tiempos productivos; en algunos casos, internacionalizar las redes (el cine por ejemplo) y en otros respetar los territorios de las naciones (el tren a diferencia del telégrafo, por ejemplo).

Por otro lado, su concepto de poder, limitado a una clase, grupo o sector social, nos parece restringido. Si aceptamos con Foucault que el poder circula por los cuerpos y éstos están disciplinados en ciertos comportamientos que permiten que el poder exista, la lectoescritura, por sí misma, disciplina el cuerpo para hacerlo funcionar en el sistema.

\section{¿QUÉ ES LO DETERMINANTE, ENTONCES?}

La vida con los demás adquiere un compromiso político. Los sujetos distintos que actúan en el espacio público tienen que expresar sus distintas necesidades, sus demandas, llegar a acuerdos, negociar y hacer pactos. Es de preocuparse que la tendencia en la actualidad es a arrojar las diferencias al espacio privado para presentarlas como meros comportamientos heterogéneos y anormales (piénsese en los reality shows y su desfile de comportamientos bizarros, principalmente sexuales), y como consecuencia, mostrar el espacio público como un lugar homogéneo de igualdad y acuerdos pacíficos.

La realidad, sabemos, es distinta. El espacio público, donde los sujetos diversos van a presentarse con todas sus diferencias para hacer acuerdos y convivir, no es ni pacífico ni armonioso. Los sujetos distintos deben saber expresar sus necesidades, sus desacuerdos, sus conflictos para dialogar, negociar y entablar pactos de convivencia social. 
De esta manera, la tarea de la educación estriba en dar formas de visibilidad y participación a los no homogéneos, a los no representativos, a los muchos diversos que todos somos. No debe temerse el conflicto que ocasionan los muchos diversos en el espacio público, sino reconocerlo y dar herramientas para solucionarlo.

En el momento actual, donde es inevitable la aparición de múltiples otros, donde el escenario público se globaliza y la acción política es esencial para la conservación del género humano, la enseñanza del lenguaje en su uso político se vuelve una necesidad inmediata. Integrar a la reflexión político-comunicativa a los muchos otros que somos, se vuelve una prioridad.

Por qué leer y escribir, desde los sujetos. Las reflexiones anteriores nos ofrecen distintos puntos de partida para comprender por qué leen los sujetos o por qué debieran hacerlo. Me refiero aquí a dos ejemplos que muestran, entre otros, que la lectoescritura, cuando es para presentarse con el otro, se ejecuta con mayor convicción, interés y cuidado.

El primer ejemplo tiene que ver con la escritura de cartas de amor. Una carta de amor, se puede suponer, es la expresión de los deseos íntimos y particulares. Sin embargo, además de ser un acontecimiento singular para los enamorados, alude también a una codificación que permite a los sujetos comprenderse, es decir, formular y asumir comportamientos sociales. Yo me aproximo a las cartas de amor como muestras de este intercambio social. Las cartas pertenecen a tres grupos sociales que muestran, a su vez, tres aproximaciones distintas al lenguaje escrito: jóvenes indígenas huicholes (grupo 1) que habitan en la Sierra Madre Occidental, que no cuentan con electricidad ni carreteras, no tienen contacto con los medios de comunicación masiva, saben escribir en castellano y conviven con prácticas orales de comunicación. Si bien cuentan con escaso material impreso, la comunidad valora la escritura y la lectura ya que los consideran necesarios para defenderse de los mestizos y del gobierno nacional. Un grupo de jóvenes (grupo 2), como la mayoría en América Latina, de bajos in- 
gresos, perteneciente a una cultura inmersa en los medios masivos de comunicación, donde la escritura tiene poca presencia y la oralidad es aún la forma más común de comunicación. El siguiente grupo de jóvenes pertenece a un grupo social privilegiado económicamente (grupo 3), que tiene acceso a todos los medios masivos de comunicación, así como a las modernas tecnologías de información y a la Internet. Estos jóvenes conviven con la escritura como una herramienta importante de comunicación y poder.

Los jóvenes manifiestan distintas apropiaciones del género epistolar (Corona 1999), y señalo en esta ocasión algunos recursos del lenguaje utilizados, como una muestra de la puesta en acción de los distintos grupos sociales.

Uno de los argumentos centrales de mi trabajo es que la escritura no es simplemente una destreza o competencia que se aprende mediante la educación formal, sino que es una forma de comunicación que se adquiere y se usa, si llega a ser relevante, de manera distinta en grupos sociales diferentes.

En las cartas de amor, los elementos que se incluyen varían según el grupo social y muestran, en sus preferencias y ausencias, sus "saberes" particulares. Definir el lugar desde donde se envía la carta es en $94 \%$ de los casos huicholes, un elemento presente, frente a las cartas de los grupos 2 y 3 , donde coinciden en no anotar el lugar de envío. La fecha aparece en $87 \%$ de las cartas de los jóvenes indígenas y sólo en $8.5 \%$ de las cartas del grupo 2; en el grupo 3, el programa de Internet se encarga de poner automática y detalladamente la fecha. Los posdatas son populares en $41 \%$ de las cartas del grupo 3 y casi ausentes, con $2.2 \%$, en el grupo 1, y $9 \%$ en el grupo 2. Es de notar el promedio de palabras por carta, que oscila entre 95 y 245, siendo el grupo 1 el que utiliza un promedio de 129 palabras, el grupo 2, 95 palabras y 245 palabras el grupo 3.

Entre otros, el análisis de las cartas muestra que no son una reproducción íntegra de las reglas de la lengua escrita sino más bien una recomposición de diferentes aspectos dada por las necesidades comunicativas de cada grupo social. 
Encuentro tres factores que determinan las múltiples escrituras: 1) el factor tecnológico de la escritura en interrelación con la oralidad, la audiovisualidad o la Internet; 2) el factor escolar y el acceso a la letra impresa, y 3) la valoración del grupo social de la forma comunicativa.

1. En cuanto al primer factor, se observan en las cartas las huellas del contexto escrito y de la oralidad o de la Internet. En las cartas huicholas encontramos un conocimiento riguroso de las reglas del código epistolar, donde se incluyen lugar y fecha en la mayoría de los casos. También se presentan características de la oralidad: la participación del espíritu comunitario que determina las formas de relación amorosa, la narrativa que usa las fórmulas rítmicas de la oralidad, y la amplia contextualización.

En las cartas de los jóvenes semiurbanos de bajos ingresos se puede observar que están apartados de la expresión escrita. La pobre ortografía, la reducida cantidad de palabras promedio por carta y el desconocimiento de las características del género, nos hace pensar que la alfabetización en este grupo ha sido formal pero no interiorizada como forma de comunicación propia. Si bien estos jóvenes viven inmersos en un contexto escrito, ya que cuentan con señalizaciones, espectaculares, volantes, productos envasados, transporte público, oficios escolares, libros de texto, propaganda política, etcétera, no son usuarios de la escritura como forma legítima de comunicarse con el otro. Las huellas de la oralidad en los escritos se observan únicamente en su uso fonético del lenguaje donde la ortografía, la puntuación y la correcta separación de las palabras, dejan mucho que desear. Sobre todo se encuentran las huellas de las formas audiovisuales de comunicación: brevedad de los mensajes, temas y formas melodramáticos, uso de imágenes decorativas y expresiones a manera de eslogans publicitarios.

Las cartas por Internet muestran una relación entre el dominio de la escritura y una forma tecnológica que facilita la conversación. Se conocen los márgenes de la carta y las reglas gramaticales del castellano escrito y, por otro lado, se experimenta con 
abreviaciones, posdatas, onomatopeyas y signos de puntuación que parecen devolver a la escritura el ritmo y gestualidad de la oralidad.

2. Los tres grupos de jóvenes asisten a la escuela secundaria y sus programas académicos formales son similares. No obstante, los jóvenes huicholes y sus maestros no hablan castellano como lengua materna, y el acceso a la cultura escrita es mínimo en la sierra donde habitan. Sin embargo, observé que este grupo no es el más lejano al dominio de la escritura. Pareciera que la valoración de la lectoescritura, como herramienta política, genera en los jóvenes una apropiación cuidadosa de dicha competencia comunicativa. De aquí que la escuela y el acceso al material escrito tienen un lugar importante en la enseñanza del descifrado y la alfabetización formal, pero no son determinantes en la diseminación de la escritura y su distribución equitativa.

3. Por último, se nota que la valoración social que se hace de la letra escrita, tiene en cada grupo un papel determinante en sus prácticas. El reconocimiento y la valoración que hacen los huicholes de la escritura define la extensión y el cuidado de sus cartas. La certeza que tienen estos jóvenes del poder de la escritura marca el compromiso que allí expresan.

El mundo altamente audiovisual en el que viven los jóvenes semiurbanos parece mantenerlos lejos de la escritura. La música y la televisión comerciales invaden su mundo y dejan poco espacio a una expresión propia. La cultura popular de estos grupos se mudó hace tiempo a lo masivo, donde sus formas de hablar han sido secuestradas por la radio y la televisión, dejando vacía su expresión escrita.

Los jóvenes que escriben por Internet pertenecientes a los grupos sociales que gozan de mayores ingresos, reflejan un dominio de la lengua escrita en combinación con la tecnología de Internet y el estilo conversacional que impregna a este género. Para estos jóvenes la escritura es una práctica cotidiana con la cual se preparan también para entrar en el mundo de quienes escriben. 


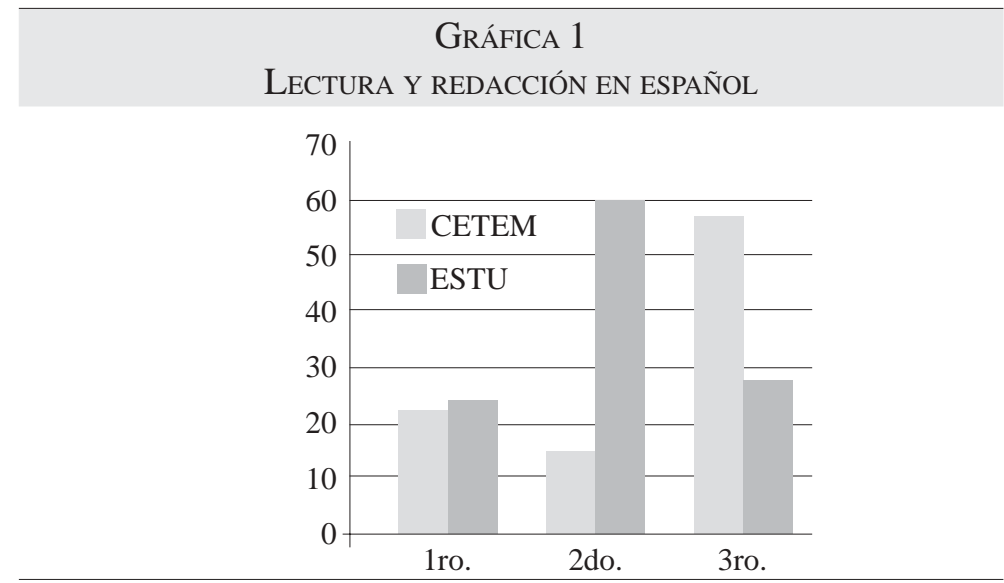

Fuente: Corona 2002b.

El segundo ejemplo tiene que ver con la cantidad de palabras utilizadas para responder a los problemas planteados durante una evaluación escolar. En este caso, responden dos grupos de jóvenes: los de primero a tercero de secundaria de una escuela indígena (grupo 1) y de los mismos grados escolares de una escuela urbana de la ciudad de Guadalajara (Corona 2002b). A partir del número de palabras promedio por texto, en este lugar reflexiono sobre la valoración comunicativa que cada grupo tiene de la escritura.

Número de palabras promedio en un texto breve. Se pidió a los alumnos de los tres grados escolares de ambas escuelas, que dieran solución a ciertos dilemas y otorgaran las instrucciones para resolverlos. A los alumnos de primer grado de la secundaria urbana de bajos ingresos (ESTU) y de la escuela secundaria huichol (CETM), se les pidió que dieran instrucciones para actuar en caso de una picadura de alacrán. A los alumnos de segundo grado de ambos grupos sociales, se pidió que dieran las instrucciones para llegar a un punto determinado cercano a la comunidad donde cada uno vive y, en tercer grado, se pidió dar instrucciones sobre qué hacer en caso de que se violen sus derechos humanos. 
La cantidad de palabras empleadas por cada grupo tiene relación con la cotidianeidad del tema, con su conocimiento y competencia para dar instrucciones así como su competencia para escribir. Puede observarse el uso de la misma cantidad de palabras promedio en el primer año de ambas escuelas para expresar lo que debe hacerse en caso de picadura: ambos coinciden en remedios caseros o visita al doctor. En el caso de segundo año, se observa un uso mayor de palabras en la escuela urbana para explicar cómo moverse en la ciudad para llegar al punto deseado, y un menor número de palabras en el caso de la escuela huichol, ya que estos últimos utilizan referencias más aproximadas a "lo que todos saben".

Ahora bien, en tercer año es de subrayar el uso mayor de palabras entre los jóvenes indígenas para explicar las instrucciones en caso de que se violen sus derechos humanos; las explicaciones de los hechos son más amplias y precisas y hacen referencias concretas a las leyes. A esta pregunta, los jóvenes urbanos de tercer grado escolar repiten el conocido eslogan publicitario que se transmite por la televisión: "mucho ojo, cuéntaselo a quien más confianza le tengas".

Estos breves datos nos ofrecen pistas para creer que cuando los textos son relevantes en el espacio público, la motivación para escribir convierte al joven en escritor activo.

\section{Conclusión}

La tendencia actual a traducir el mundo a imágenes publicitarias, cibernéticas y televisivas, parece conducir a que los hombres piensen en imágenes y no en palabras. Mi propuesta, inscrita en este mundo hipervisualizado, reconoce que la esfera pública para el libro y para la cultura de la escritura, tiene que ser recreada. Debe ser construida a partir de un espacio donde la lectura equilibre a la imagen y ayude a tomar distancia frente a lo que ve el ojo, donde pese la razón que emana del libro y de la cultura escrita y donde se valore la lectura por lo menos como el consumo de tenis de marca, de la última versión del Play Station o de las novedades de MTV. 
Por otro lado, la enseñanza de la lectoescritura como forma de divertimento o como acceso abstracto a la cultura, no se sostiene por sí sola. Enseñar a leer y escribir debe tener como objetivo participar en el espacio público. Debe facilitar la participación en el espacio donde yo aparezco ante los otros y los otros ante mí, no sólo como cosas vivas, sino como seres que buscan su visibilidad y que, gracias a que son distintos y lo reconocen frente a los demás, adquieren realidad.

La unicidad de los seres humanos implica dominar las herramientas del lenguaje, allí incluidas la lectura y la escritura, para poder participar con la pluralidad de los seres que habitan este planeta.

Los ejemplos mostrados parecen decir que los jóvenes encuentran relevante la lengua escrita cuando es para presentarse con los otros. Reconozco que ningún grupo estudiado es lector. Lo puedo constatar en la forma oral de su expresión y en su limitado conocimiento de la ortografía, la sintaxis y la separación de las palabras. Sin embargo podemos observar, por la cantidad de palabras, por los contenidos y por el cuidado de los textos, la valoración comunicativa que distintos grupos le otorgan a los escritos. Mi propuesta va en el sentido de recuperar esta intuición política para enseñar a leer y escribir mejorando las posibilidades de los hombres de vivir en su conjunto.

\section{REFERENCIAS BIBLIOGRÁFICAS}

Arendt, Hanna (2001) Hombres en tiempos de oscuridad. España: Gedisa.

— (1997) ¿Qué es la política? España: Paidós.

(1993) La condición humana. España: Paidós.

(1996) “La crisis de la educación”, Entre el pasado y el futuro. Barcelona:

Península.

Bajtín, M.M (1985) Estética de la creación verbal. México: Siglo xxi Editores. — (2000) Yo también soy (Fragmentos sobre el otro). México: Taurus.

Bourdieu, Pierre (1990) Sociología y cultura. México: Grijalbo/Conaculta.

Corona, Sarah (2002a) Miradas entrevistas. Comunicación visual y fotografía huichol. México: Universidad de Guadalajara/Conacyt.

- (2002b) Centro Educativo Tatutsi Maxakwaxi, evaluación 2001-2002. México: Fundación Ford/ITESo. 
(1999) "Competencias comunicativas de la escritura en huicholes y mestizos", en Comunicación y Sociedad, núm. 35. Guadalajara: Universidad de Guadalajara, pp. 151-166.

_ - y Evelyn Diez-Martínez (1993) "El libro como objeto cultural. Un estudio comparativo con niños de dos grupos sociales", en Comunicación y Sociedad, núm. 18-19. Guadalajara: Universidad de Guadalajara, pp. 47-66.

_- y Salvador Agustín (2002) Nuestro libro de la memoria y la escritura. Apuntes para la enseñanza de la cultura wixarika. Guadalajara: Universidad de Guadalajara.

FIJALKow, Jaques (1986) Mauvais lecteurs, pourquois? París: PUF.

Finnegan, Ruth (1988) Literacy and Orality. Studies in the Technology of Communication. Gran Bretaña: Basil Blackwell.

Foucault, Michel (1969) Las palabras y las cosas. México: Siglo xxi Editores. Giroux, Henry A. (1998) La escuela y la lucha por la ciudadanía. México: Siglo XXI EDITORES.

Havelock, Eric A. (1963) Preface to Plato. Harvard: The Belknap Press of Harvard University Press.

— (1986) The muse learns to write. Reflections on orality and literacy from antiquity to the present. Yale: Yale University Press.

Goody, Jack (comp.) (1996) Cultura escrita en sociedades tradicionales. Barcelona: Gedisa.

Herrera Beltrán, Claudia (2003) "OCDE: el rendimiento escolar en México, sin mejoría en dos años", La Jornada, 1 de julio, México.

KRASHEN, Stephen D. (1984) Writing: Research, theory and applications. Laredo: Laredo Publishing.

Lévi-Strauss, Claude (1992) Tristes trópicos. España: Paidós.

Martín Barbero, Jesœs (2001) "De las políticas de comunicación a la reimaginación de la política", Nueva Sociedad, núm. 175, octubre, Caracas.

McLuhAn, Marshal (1964) La comprensión de los medios como las extensiones del hombre. México: Diana.

— (1969) "Marshall McLuhan: entrevista", en Playboy, marzo, EuA.

ONG, Walter (1985) Orality and Literacy. The Technologizing of the Word. EuA: Methuen.

SalazAR Embarcadero, Juan José (2003) "La lectura en México: Los proyectos y los programas", Libros de México, núm. 70, agosto-octubre. México: Cámara Nacional de la Industria Editorial Mexicana.

SEnNETt, Richard (2003) El respeto. Sobre la dignidad del hombre en un mundo de desigualdad. Barcelona: Anagrama.

Touraine, Alain (1997) ¿Podremos vivir juntos? México: FCE.

_- (1999) Igualdad y diversidad. Las nuevas tareas de la democracia. MéxiCO: FCE.

Wolton, Dominique, "Las contradicciones de la comunicación política", en: Gilles Gauthier, André Gosselin y Jean Mouchon (com.) Comunicación y política, Gedisa, Barcelona, 1995, pp. 110-132. 